\title{
Comparative Study of Methodologies for Schedule Management in an Environment of Multiple Simultaneous Projects
}

\author{
Thalisson de Brito Dinelli, Marcelo Albuquerque de Oliveira, \\ Raimundo Kennedy Vieira, and Erika Souza de Melo
}

\section{ABSTRACT}

\begin{abstract}
A project is a unique event that has an established deadline and with a purpose to meet a specific need of the team interested in the project. The objective of this work was to identify which method would be the most adequate for the reality of the studied environment and to show the benefits and losses in the adoption of each one of these methods. To achieve this objective, an analysis of 25 projects was carried out between the years of July 2019 and June 2019 to obtain a sufficient database and with these data to carry out a comparative study between three different methods of estimating deadlines in relation to what was actually practiced. The projects were divided into six main stages, the opening of the project, approval of the purchase order, delivery, confirmation of the start of operations, capitalization of assets and closing of the project. The first stage of data collection was to capture the number of days required to complete each stage in each of the 25 projects analyzed and thereby calculate minimum, maximum and average points of execution. With the data obtained from these projects, a simulation was made for the case of using the adapted media, Pert and Pert methodology. The studied environment has as a singularity the occurrence of multiple simultaneous projects and taking place in different stages. After comparative analyzes, it was Pert for presenting a greater balance between the metrics "projects within the deadline" and "variation of project $X$ actual," however, the study also showed a lot of instability in the processes studied, so future studies to understand the discrepancy for the amount of days needed to perform a similar activity on different projects.
\end{abstract}

Keywords: Average time, PERT, Project management, Project schedule.
Submitted : May 10, 2021

Published : June 04, 2021

ISSN: $2507-1076$

DOI: $10.24018 /$ ejbmr.2021.6.3.886

\section{T. B. Dinelli}

Federal University of Amazonas, Brazil. (e-mail: thalisson.dinelli@yahoo.com.br) M. A. de Oliveira*

Federal University of Amazonas, Brazil.

(e-mail: marcelooliveira@ ${ }^{\circledR}$ uam.edu.br)

R. K. Vieira

Federal University of Amazonas, Brazil.

(e-mail: kennedy71@gmail.com)

E. S. de Melo

Université du Québec à Trois-Rivières,

Canada.

(e-mail: Erika_SouzadeMelo@uqar.ca)

*Corresponding Author

\section{INTRODUCTION}

Seen as one of the areas of knowledge in project management according to [1], schedule management is essential, as it is possible to achieve one of the main success criteria, which is delivery within the established deadline. This parameter is common for all types of projects, from the simplest to the most complex.

The Chaos report [2], developed by the Standish Group, evaluated during the period from 1994 to 2015, more than 50,000 projects and Lynch points out that in this report, in the period from 2011 to 2015, the rate of projects that underwent changes during its execution was between $49 \%$ and $56 \%$. The reasons for these delays are diverse, such as, for example, non-compliance with deadlines by suppliers, lack of quality or rework in certain stages of the project or even the incorrect estimate of time to carry out the activities.

This work aimed to analyze the history of 25 projects with similar scopes and understand which method should be used to estimate the deadlines within the projects in order to reduce the amount of changes in projects due to delays in the process of accepting deliveries without overestimate activities, thus managing to share with all interested parties a feasible deadline for the completion of deliveries. The projects considered in this study are low complexity projects. Small Projects [3] are projects that have the following characteristics:

- Short-term projects;

- Number of members less than 10 people;

- They involve few areas of knowledge;

- Objectives easily attainable;

- Well-defined scope;

- Affect a single business area;

- They do not present great political divergences as to whether or not to proceed with the project;

- Produce deliveries with little interdependence between different areas of knowledge;

- Projects with a budget of less than 150,000 USD.

The projects studied during this research have all these characteristics mentioned above. For that, a comparison of all the planned and executed schedules of each of these projects was made and observed which activities impacted the noncompliance with the deadlines. Then, after analyzing the data, post-fact planning was done and the PERT tools, three points 
and average were applied to observe, which is the best among these tools to estimate the deadlines and obtain a higher percentage of assertiveness in the planned schedule compared to the deadlines executed.

This work was carried out in a company in the industrial pole of Manaus, and only projects from the fiscal year between July 2019, and June 2020 were considered for this study. Projects with WBS different from the vast majority were also excluded from the study, for greater accuracy in comparing the analyzed data.

\section{LITERATURE REVIEW}

Projects [4], [5] are unique events, with a defined deadline for their realization and exist to meet specific needs.

Projects can be divided into five main stages: initiation, planning, execution, monitoring/control and closure.

Another way to subdivide project is through the areas of knowledge. According to PMBOK [1], projects can be subdivided and managed in ten areas of knowledge, namely: Project integration management, Project scope management, Schedule management, Cost management, Quality management, Project resource management, Communications management, Risk management, Project procurement management, and Project stakeholder management.

Schedule management was known until the fifth edition of PMBOK [1] as time management, however, this nomenclature was changed since time cannot be managed, but the schedule is. The idea at this stage is to seek the closure to the project within the established time limit. For that, it is necessary to correctly manage the estimate of tasks, necessary resources and deadline.

Furthermore, according to the PMBOK [1], for the development of the schedule, it is necessary to create a list of activities, activity attributes, network diagrams, resource requirements, resource availability calendar, and estimated duration of activities, scope definition, environmental factors and the assets of organizational processes.

Among these sub-steps of the schedule management, the estimated duration of activities requires knowledge from the manager and a method to carry out the estimates. These time estimates can be defined through pre-established agreements or through the history of old projects.

PERT (Program Evaluation and Review Technique) is a technique that uses time as a variable in planning, organizing, and coordinating activities [6]. The PERT tool takes into account random variables related to each other and with some degree of probabilistic distribution [7].

The following information can be obtained through the application of this tool [8]:

- The duration of the project or of a stage and its respective critical paths;

- The probability of completion within the established time;

- The probability taking as a reference a deadline.

The technique helps to understand the most suitable period for carrying out an activity by performing a weighted average using the most positive scenario (p), the most negative scenario (n) and the most common (c) or probable scenario.
The formula for this calculation [9] is shown in (1):

$P=\frac{p+4 c+n}{6}$

$\mathrm{P}=$ Average time;

$\mathrm{p}=$ Pessimistic forecast;

$\mathrm{c}=$ Most likely forecast;

$\mathrm{n}=$ More optimistic forecast.

Applying this equation, the result of the average time tends to be close to the most likely forecast, as it is multiplied by 4 . Therefore, this scenario has more relevance in this calculation.

There are several ways to estimate schedules [10], which can be done through the opinion of an expert, or through comparisons with histories of similar projects, for example. Another alternative is to use the three-point tool, which has a calculation similar to that presented in Equation 1, but all scenarios have the same relevance in the calculation presented in (2).

$P=\frac{p+c+n}{3}$

$\mathrm{P}=$ Average time;

$\mathrm{p}=$ Pessimistic forecast;

$\mathrm{c}=$ Most likely forecast;

$\mathrm{n}=$ More optimistic forecast.

The disadvantage of this adaptation is that the average time found may have a greater variation in relation to the most likely forecast. As there is no multiplying factor, as in PERT, there may be an oversized deadline for carrying out an activity. The advantage of this adaptation is that there may be a more conservative approach to deadlines, ensuring a greater number of projects on schedule.

\section{Methodology}

This work sought to understand the behavior of the schedule of 25 projects within a consumer goods company from July 2019 to June 2020. In this work, only projects with a similar scope, which can be divided into open, were considered in this work: approval of purchase order; delivery and confirmation of the beginning of operations; capitalization of assets; and closing of the project.

The methodological path adopted for the work is shown in the following steps, as shown in Fig. 1.

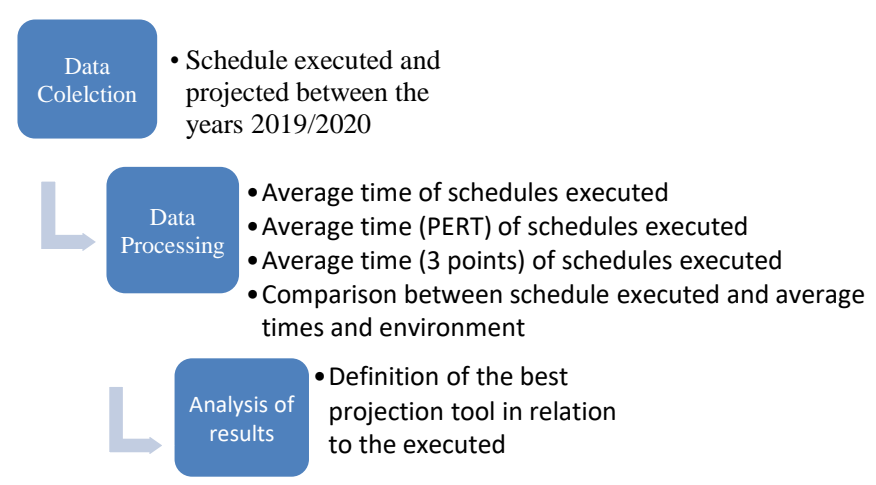

Fig 1. Methodological path adopted for the study. 
The first step in the execution of data collection was the gathering of information related to the expected deadlines for the completion of each stage of the projects and the deadline actually executed in each of these stages in each of these projects.

With this information, it was possible to calculate the average variation in compliance with the schedule as well as the absolute number and percentage of projects within the planned period.

Then, it was possible to apply the PERT, 3 Points Adapted and Average tools in order to have a reference for comparing these three tools with what was performed in practice. The number of days required for the execution of each of the stages and for each of the projects was taken into account for the calculation.

For application in the equations, data were collected on the number of days to complete each step in each of the analyzed projects. The most likely forecast was calculated by adding the days needed to complete the steps in each of the projects, dividing this amount by the total number of projects analyzed.

For the PERT and Three Points calculation, the worst performance among all projects in each of the stages was identified to define the most pessimistic forecast and the best performance among all projects in each of the stages to define the most optimistic forecast.

With that, it was possible to identify which of these three tools, if applied in the project planning phase, would present a higher percentage in the planned $\mathrm{x}$ executed ratio as well as less variation. In this way it is possible to understand the positive and negative points of using each of these tools.

The projects were divided into 6 stages: Opening of the project, approval of the purchase order, delivery, confirmation of the start of activities, capitalization of the asset and closing of the project and these tools were applied to each of these stages.

This work has an applied nature, because the knowledge referenced will be replicated within the researcher's profession and the knowledge obtained will come from this application in the daily life of the project manager. As for the objective, the research is classified as exploratory, since the researcher seeks to deepen his knowledge of the subject addressed. Research with exploratory objectives identifies concepts, models development and seeks information from similar studies [11].

In relation to data processing, this is a quantitative and qualitative research, as it aims to translate the perception of waste, from the perspective of project managers, into numbers and propose actions to reduce this waste.

Then, the metric of the impact of these actions will be raised. As for the procedures, this research is classified as an action research, as there is direct participation of the author in the processes that will be addressed. Action research allows the researcher to participate in understanding problems and solving them.

The research was carried out in the project management department of a multinational company located in the industrial pole of Manaus. The chosen environment is also the place where the researcher develops his professional activities.

\section{FINDING AND DISCUSSIONS}

This analysis of results was divided into six stages: Opening of the project, Approval of the Purchase Order, Delivery, Confirmation of the beginning of operations, Capitalization of assets and Closing of the project. At each stage, a comparison was made between the practiced dates and the projected dates based on the Average, PERT and Adapted Three Points.

Regarding the project opening stage, we can see the following behavior observed in Table I: In the first column (Real), the values practiced within the projects are presented, in the first line (Average) the average calculation of days that were necessary for this stage of the project.

In the second line (Projects within the deadline) it presents the number of projects that were within the deadline stipulated in the opening of each of these projects.

In the third line (\% projects within the deadline) a percentage calculation of the relationship between projects within the term and the total number of projects.

In the last line (Projected vs. Actual Variation), the average of the projected days ratio and the number of days required for the execution of each project are observed. The same rationale was used for Tables II, IV, V, and VI.

TABLE I: DATA PRoJeCtion - OPENING OF PROJECTS

\begin{tabular}{ccccc}
\hline \hline & Real & Average & 3 Points & PERT \\
\hline Average & 7 & 7 & 13 & 10 \\
On-time projects & 15 & 18 & 22 & 20 \\
$\%$ projects on time & $58 \%$ & $69 \%$ & $85 \%$ & $77 \%$ \\
$\begin{array}{c}\text { Variation (Projected } \\
\text { vs. Actual) }\end{array}$ & $169 \%$ & $105 \%$ & $57 \%$ & $73 \%$ \\
\hline \hline
\end{tabular}

Regarding the Purchase Order Approval step, Table II shows the following information:

\begin{tabular}{lcccc}
\multicolumn{5}{c}{ TABLE II: DATA PROJECTION - PURCHASE ORDER } \\
\hline \hline & Real & Average & 3 Points & PERT \\
\hline Average & 22 & 22 & 26 & 26 \\
On-time projects & 13 & 15 & 15 & 15 \\
$\%$ projects on time & $52 \%$ & $60 \%$ & $60 \%$ & $60 \%$ \\
Variation (Projected & $295 \%$ & $102 \%$ & $83 \%$ & $83 \%$ \\
vs. Actual) & & &
\end{tabular}

Regarding the data of the Delivery stage, it was necessary to carry out a percentage variation survey, as the projects do not have the same manufacturing term by the customer, and therefore cannot be compared using the variable number of days. The data are shown in Table III.

\begin{tabular}{lcccc}
\multicolumn{5}{c}{ TABLE III: DATA PROJECTION - DELIVERY } \\
\hline \hline & Real & Average & 3 Points & PERT \\
\hline Average & $94 \%$ & $94 \%$ & $94 \%$ & $94 \%$ \\
On-time projects & 17 & 16 & 16 & 16 \\
$\%$ projects on time & $68 \%$ & $64 \%$ & $64 \%$ & $64 \%$ \\
$\begin{array}{l}\text { Variation (Projected } \\
\text { vs. Actual) }\end{array}$ & $94 \%$ & $94 \%$ & $94 \%$ & $94 \%$ \\
\hline \hline
\end{tabular}

Table IV presents the data referring to the Confirmation of the start of operations step, as shown below.

Table $\mathrm{V}$ shows the data related to the capitalization of assets stage.

Finally, Table VI shows the data collected from the last stage, here called Project Closure. 
TABLE IV: DATA PROJECTION - CONFIRMATION OF THE START OF OPERATIONS

\begin{tabular}{lcccc}
\multicolumn{5}{c}{ OPERATIONS } \\
\hline \hline Real & Average & 3 Points & PERT \\
\hline Average & 26 & 26 & 40 & 33 \\
On-time projects & 11 & 11 & 18 & 14 \\
$\%$ of projects on time & $44 \%$ & $44 \%$ & $72 \%$ & $56 \%$ \\
Variation (Projected & $155 \%$ & $117 \%$ & $76 \%$ & $92 \%$ \\
vs. Actual) & & &
\end{tabular}

TABle V: DATA PRojection - CAPITAlization of Assets

\begin{tabular}{lcccc}
\hline \hline & Real & Average & 3 Points & PERT \\
\hline Average & 27 & 27 & 29 & 38 \\
On-time projects & 12 & 16 & 16 & 16 \\
$\%$ of projects on time & $48 \%$ & $64 \%$ & $64 \%$ & $64 \%$ \\
$\begin{array}{l}\text { Variation (Projected } \\
\text { vs. Actual) }\end{array}$ & $128 \%$ & $102 \%$ & $102 \%$ & $102 \%$ \\
\hline \hline
\end{tabular}

TABLE VI: DATA PROJECTION - PROJECT ClOSURE

\begin{tabular}{lcccc}
\hline \hline & Real & Average & 3 Points & PERT \\
\hline Average & 17 & 17 & 19 & 18 \\
On-time projects & 25 & 12 & 14 & 13 \\
$\%$ of projects on time & $100 \%$ & $48 \%$ & $48 \%$ & $52 \%$ \\
Variation (Projected & $37 \%$ & $98 \%$ & $88 \%$ & $93 \%$ \\
vs. Actual) & & &
\end{tabular}

Table VII consolidates all the previous tables, with the exception of the closing phase of the project, as this was the only step that presented over-dimensioning behavior of the schedule.

TABLE VII: DATA PROJECTION - DATA CONSOLIDATION

\begin{tabular}{lcccc}
\hline \hline & Real & Average & 3 Points & PERT \\
\hline$\%$ of projects on time & $54 \%$ & $61 \%$ & $70 \%$ & $65 \%$ \\
$\begin{array}{l}\text { Variation (Projected } \\
\text { vs. Actual) }\end{array}$ & $169 \%$ & $106 \%$ & $82 \%$ & $90 \%$ \\
\hline \hline
\end{tabular}

\section{CONCLUSION}

In general, it was observed that a relevant variation in basically all stages of project management occurred. The stage with the least discrepancy, that is, with the "Variation (Projected vs. Real)" ratio closest to $100 \%$ was in the "Delivery" stage, which is the only stage that depends exclusively on suppliers external to the company, thus denoting that internal processes need to be revised to stabilize estimated deadlines.

The step with the greatest variation was the "Purchase Order Approval" which, in addition to presenting a variation in the project $\mathrm{x}$ real ratio equivalent to $295 \%$, still had a low adherence of projects within the estimated (52\%). This step can be seen by the company as a focus for acting on process improvements, aiming at stabilizing the process and reducing the impact on the schedule.

However, there was also an overestimation of deadlines in one of the stages. The closing phase of the project was the only one that presented a percentage of projects within the estimated timeframe above $80 \%$, in this stage all projects were on schedule, however the projected $\mathrm{x}$ actual variation was $37 \%$, which shows that necessary for this stage could be $63 \%$ lower, for this reason, this stage was disregarded in the average analysis between all stages of the project.

Comparing the studied forecasting models, the Adapted Three-Point model is the one that presents the best ratio\% of projects within the deadline, however, among the options, it is also the model that presents the greatest variation in the projected $\mathrm{x}$ real ratio. Applying this model, it is possible to reduce the number of changes, and provide a more reliable schedule for the completion of the project, but it is necessary to stabilize the processes to avoid variations and to avoid over dimensioning deadlines. Through the data collected, the model that presents greater stability, both in the percentage of projects inside, as well as in the real x project variation would be PERT. Thus, the model recommended by this study for estimating deadlines is PERT.

The objective of this work was to indicate a model for estimating the schedule in order to provide greater security to the interested parties regarding the deadlines for carrying out the activities. However, during the study, there was a lot of instability in the processes. For example, in the opening phase of the project, while one of the projects was opened in three days, another project was opened in twenty-six days. As future work, it is recommended to apply tools that stabilize the processes within the project management for this environment.

\section{ACKNOWLEDGMENTS}

The authors thank the Postgraduate Program in Production Engineering (PPGEP) of the Federal University of Amazonas (UFAM) for their support and structure. This work was carried out with the support of the Amazonas State Research Support Foundation (FAPEAM) under PosGrad Program.

\section{REFERENCES}

[1] PMI. Project Management Body of Knowledge (PMBOK® Guide Sixth Edition - 2017).

[2] Lynch, J. (2015). Standish Group 2015 Chaos Report. Available at https://www.infoq.com/articles/standish-chaos-2015.

[3] Rowe, S. (2020). Project management for small projects. BerrettKoehler Publisher, inc. Oakland.

[4] Carvalho, A. B., Abreu, I. M. C., Pedrozo, I. F. (2013) Fluxograma como ferramenta de aperfeiçoamento e de controle em instituições públicas. Revista de Administração da UFSM, v. 6, n. 2, p. 373-394.

[5] Amaral, M. (2005). Technology innovation and project management: building bridges across triple helix way. In: International Triple Helix Conference, 5, 2005, Turin. Anais... Turin: Triple Helix, 2005. p. 1-13.

[6] Cynthia O. U. (2020) Implementation of Project Evaluation and Review Technique (PERT) and Critical Path Method (CPM): A Comparative Study. Int J Ind Operations Res 3:004.

[7] Luiz, E. L. A. (2011). Otimização da relação tempocusto na construção civil: um estudo de caso. Ribeirão Preto: USP.

[8] Danielson, C. \& Khan, H. (2015). Risk Analysis of project time and cost through Monte Carlo Method, Tese de doutorado, Stockholm, Sweden.

[9] Andrade, E. L. (2004). Introdução à Pesquisa Operacional - Métodos e Modelos para Análise de Decisões. LTC.

[10] Heusner, M. M. (2020). Gerenciamento do cronograma em obras de infraestrutura: Um estudo de caso, Ijuí.

[11] Miguel, A. (2010). Gestão de Projectos de Software (4 ${ }^{\mathrm{a}}$ ed.). Lisboa, Portugal: FCA - Editora de Informática.

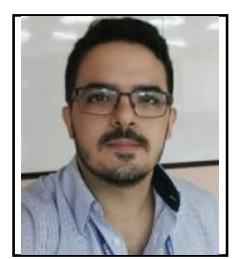

Thalisson Dinelli is a student in the master's Program in Production Engineering at Federal University of Amazonas, who was born in Manaus/AM, 1989. He has completed and his bachelor's degree at Federal University of Amazonas, Manaus/AM, Brazil, 2015, in Production Engineering and after he concluded his post-graduation studies in innovation management for industrial process at Fucapi, Manaus/AM, Brazil, 2016. He works as Project Coordinator for a multinational company since 2019 


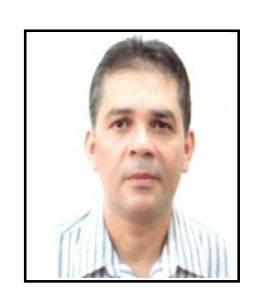

Marcelo Oliveira is an Adjunct Professor of Department of Production Engineering and member of Master Program in Production Engineering, Federal University of Amazonas. He has published several Research Papers related to Engineering area.

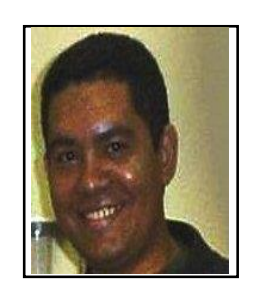

Raimundo Kennedy is a Head Professor of Department of Civil Engineering and member of Master Program in Production Engineering, Federal University of Amazonas. He has published several Research Papers related to Engineering area.

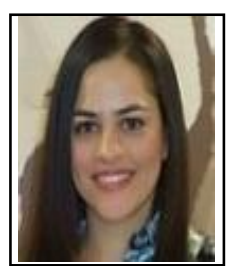

Erika Melo is a Visitant Professor of Université du Québec à Trois-Rivières (UQTR) and member contributor of Master Program in Production Engineering, Federal University of Amazonas. She has published Research Papers related to Engineering area and Aeronautical Project Management. 